\section{Comparison of the methods of fibrinolysis by tube thoracostomy and thoracoscopic decortication in children with stage II and III empyema: a prospective randomized study}

Ufuk Cobanoglu, Fuat Sayır, Salim Bilici,

Mehmet Melek,

Abidin Şehitoğlu, Van State Hospital Department of Thoracic Surgery, Van, Turkey

\section{Abstract}

Today, in spite of the developments in imaging methods and antibiotherapy, childhood pleural empyema is a prominent cause of morbidity and mortality. In recent years, it has been shown that there has been an increase in the frequency of pleural empyema in children, and antibiotic resistance in microorganisms causing pleural empyema has made treatment difficult. Despite the many studies investigating thoracoscopic debridement and fibrinolytic treatment separately in the management of this disease, there is are not enough studies comparing these two treatments. The aim of this study was to prospectively compare the efficacy of two different treatment methods in stage II and III empyema cases and to present a perspective for treatment options.

We excluded from the study cases with: i) thoracoscopic intervention and fibrinolytic agent were contraindicated; ii) immunosuppression or additional infection focus; iii) concomitant diseases, those with bronchopleural fistula diagnosed radiologically, and Stage I cases. This gave a total of 54 cases: $23(42.6 \%)$ in stage II, and $31(57.4 \%)$ cases in stage III. These patients were randomized into two groups of 27 cases each for debridement or fibrinolytic agent application by video-assisted thoracoscopic decortication (VATS). The continuity of symptoms after the operation, duration of thoracic tube in situ, and the length of hospital stay in the VATS group were of significantly shorter duration than in the streptokinase applications $(\mathrm{P}=0.0001)$. In 19 of 27 cases $(70.37 \%)$ in which fibrinolytic treatment was applied and in 21 cases of 27 (77.77\%) in which VATS was applied, the lung was fully expanded and the procedure was considered successful. There was no significant difference with respect to success rates between the two groups $(\mathrm{P}=0.533)$. The complication rate in our cases was $12.96 \%$ and no mortality was observed. Similar success rates in thoraco- scopic drainage and enzymatic debridement, and the low cost of enzymatic drainage both served to highlight intrapleural streptokinase treatment as a reliable method in reducing the need for surgery in complicated empyema.

\section{Introduction}

Bacterial pneumonia in children is frequently complicated by pleural effusion and its incidence varies between 20 and 91\%.1-3 When pleural effusion is treated with appropriate antibiotics, it generally recovers spontaneously. When treated inappropriately, as a result of fibrin deposition, the accumulation of bacterial products and leukocytes in the pleural cavity and complicated parapneumonic effusion develop. ${ }^{1}$

Causes such as socioeconomic insufficiency, insensible antibiotic use, pneumonia findings which mask the symptoms of empyema resulting in delayed diagnosis, use of antibiotics only in the acute stages, and consequent delays in referral to a thoracic surgery unit, all play a role in the conversion of parapneumonic effusion to empyema.

According to the classification of the American Thorax Association, empyema develops in three different stages: ${ }^{4}$ stage I (exudative), fluid accumulation, $\mathrm{pH}$ over 7.2, lactate dehydrogenase below $1000 \mathrm{IU} / \mathrm{L}$, glucose over $60 \mathrm{mg} / \mathrm{dL}$, negative culture and no loculations; stage II (fibrinopurulent), $\mathrm{pH}$ below 7.2, lactate dehydrogenase over $1000 \mathrm{IU} / \mathrm{I}$, glucose below $60 \mathrm{mg} / \mathrm{dL}$, increased loculation or positive culture or presence of suppuration in the pleural cavity by fibrin deposition (empyema); stage III (organized), in addition to stage II, organized multiloculated parapneumonic effusion, trapped lung and pleural cortex formation.

Treatment options for this disease are observation, therapeutic thoracentesis, tube thoracostomy, intrapleural fibrinolytics, decortication with thoracoscopy and thoracotomy, and open drainage procedures. 5,6

In the progress of a thoracic empyema or complicated (persistent or loculated) parapneumonic effusion, viscous fluid with obstructing fibrinous debris and non-communicating fluid locules may develop; a single thoracic tube for drainage remains insufficient. ${ }^{7,8}$ Insufficient treatment in the fibrinopurulent period causes pleural fluid organization and scar formation in the pleural cavity and the neighboring lung tissue. ${ }^{7}$ In order to prevent this, and to clear out the fibrinous debris, numerous studies suggest video-assisted thoracoscopic decortication (VATS) or fibrinolytic treatment in the early stages.1,9-11

The aim of this study was to prospectively compare thoracoscopic debridement and fibrinolytic treatment in cases with stage II and III
Correspondence: Ufuk Cobanoglu, Medical schooll, University of Yuzuncu Yil, Van, Turkey. Tel.+90.432.215.0473 - Fax: +90.432.2168352.

E-mail: drucobanoglu@hotmail.com

Key words: child, empyema, fibrinolysis, thoracoscopic decortication.

Received for publication: 10 June 2011. Revision received: 23 July 2011.

Accepted for publication: 26 October 2011.

This work is licensed under a Creative Commons Attribution NonCommercial 3.0 License (CC BYNC 3.0).

(C) Copyright U. Cobanoglu et al., 2011

Licensee PAGEPress, Italy

Pediatric Reports 2011; 3:e29

doi:10.4081/pr.2011.e29

empyema and to present a perspective for treatment options.

\section{Materials and Methods}

Cases with contraindication against thoracoscopic intervention and fibrinolytic agent treatment, those with immunosuppression or additional infection foci, those with other simultaneous diseases, those with radiological bronchopleural fistulae and atage I cases were excluded from the study. A total of 54 cases, 23 (42.6\%) in stage II and 31 (57.4\%) in stage III, were randomized into two groups of 27 patients each for debridement by VATS or fibrinolytic agent administration (Figure 1). Patients with hemorrhagic diathesis, stroke or manifest hemorrhage having occurred in the previous six months and those who had used fibrinolytic agents for any reason in the previous two years were excluded from the fibrinolytic treatment group.

Patients' legal guardians and the institutional ethics committee gave their consent before beginning the study.

A detailed history of disease was obtained from all cases, physical examinations were performed and the duration of symptoms for each case was evaluated.

Eighty percent of cases lived in villages and hamlets and were children of families of a low socioeconomic level. The duration of symptoms was measured as a mean of 7.9 days (range 4-10 days); difficulties in transportation and fear of terrorist attacks played a role in this delay. No treatment was received prior to hospitalization in $76.3 \%$ of the cases; others had used antibiotics irregularly.

Following chest X-ray confirmation of pleural fluid, ultrasonography and computerized tomography, and diagnostic thoracentesis 
were performed. The number of cells and the cell characteristics were determined in the pleural fluid. Furthermore, the $\mathrm{pH}$, protein, glucose, lactate dehydrogenase and density measurements in the pleural fluid and simultaneous serum protein, serum glucose and lactate dehydrogenase measurements were taken. The pleural fluid was sent for Gram staining and culture. The presence of the following characteristics in the thoracentesis fluid led to the diagnosis of empyema: $\mathrm{pH}$ <below 7.2, glucose below $60 \mathrm{mg} / \mathrm{dL}$, protein over $3 \mathrm{~g} / \mathrm{dL}$, LDH over $1000 \mathrm{IU}$, leukocyte over $5 \times 10 \% / \mathrm{L}$ or presence of bacteria in direct examination or culture of the pleural fluid.

In patients who were diagnosed with empyema, as suggested in the book of Pediatric Respiratory Medicine, 12 empiric treatment with ampicillin sulbactam plus cefotaxime was initiated. This regime was then changed when necessary according to culture results.

An 18-24 Fr chest tube was initially inserted in all cases and connected to a closed drainage system and $15-20 \mathrm{cmH}_{2} \mathrm{O}$ negative suction was applied. Thoracic tube insertion was performed in the operating theater under intravenous sedation and monitorization.

In 27 cases undergoing video-assisted thoracoscopic surgery, routine pulse oximetry, ECG, non-invasive blood pressure monitoring and end-tidal $\mathrm{CO}_{2}$ measurements were routinely performed during the anesthesia. During the procedure, the patients were placed in the lateral decubitis position. Video equipment was placed on both sides of the head. In all cases, a $5 \mathrm{~mm} 30^{\circ}$ scope (Karl Storz, Tuttlingen, Germany) was used. The fifth or sixth intercostal space in the mid-axillary line was selected as the primary port $(5 \mathrm{~mm})$ site. The apical port $(10 \mathrm{~mm})$ was inserted through the third intercostal space in order to better visualize the costophrenic sinus, diaphragm and the inferior region. The third port (10 $\mathrm{mm}$ ) was inserted at the auscultation triangle in order to explore the anterior thoracic wall and mediastinal structures. During the thoracoscopy, the mediastinum, the pericardium, the chest wall, the lung and the diaphragm were carefully investigated. Large cup forceps were used to clear the debris. Fluid and debris particles were sent for culture. When the procedure was brought to an end, the ports were removed under direct vision and insertion of the 18-24 Fr thoracic tube into the intrapleural space followed. Following this, for the other 27 cases in which a remarkable amount of fluid persisted despite drainage of less than $50 \mathrm{~mL}$ determined by ultrasonography and direct chest X-ray, enzymatic debridement was performed using streptokinase (STK) (Streptase; Hoechst, Istanbul). Before and after the fibrinolytic treatment, the prothrombin time, activated partial thromboplastin time (aPTT) and fibrinogen were measured and a complete blood count was performed. Following steroid and antihistaminic treatment as pre-medication, the patients were laid on one side where the lesion was in the upper position. Normal saline with 250,000 U/100 mL STK was administered into the pleural cavity through the thoracic tube in 70-120 mL volume once a day and the tube was held by a clamp for $4-6 \mathrm{~h}$. The period of fibrinolytic treatment was determined as 4.45 days (3-5 days). The first drainage fluid was sent for culture and the thoracic tubes were connected to a $-15-20 \mathrm{~cm} \mathrm{H}_{2} 0$ negative suction after the clamp was opened.

The pleural fluid drainage, after the videoassisted thoracoscopic surgery and STK application, were recorded for $24 \mathrm{~h}$.

In the VATS cases, conversions to minithoracotomy, and in the fibrinolysis cases, conver-

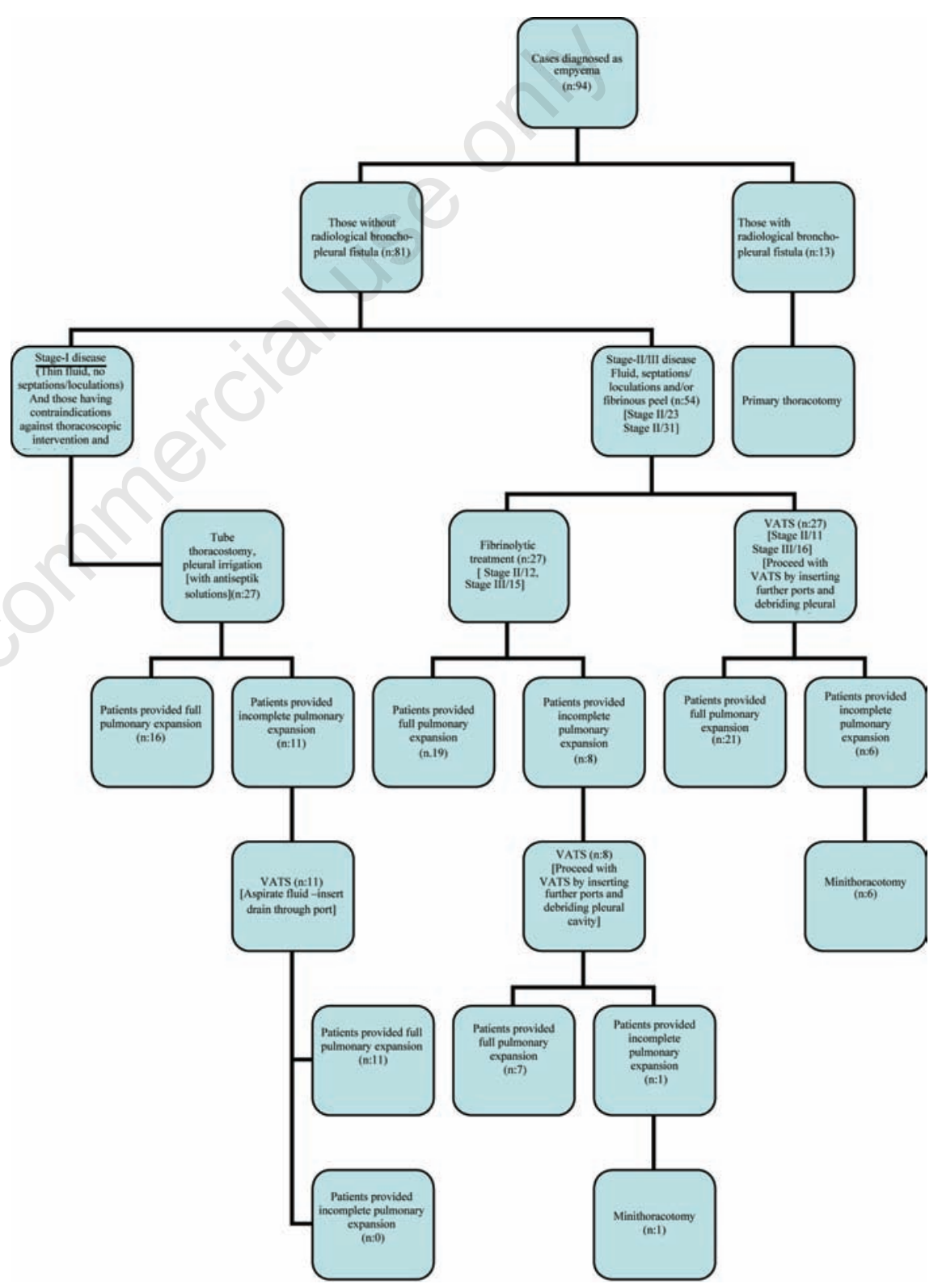

Figure 1. Treatment algorithm applied in children with empyema. sions to VATS were considered failures.

Radiological recovery was assessed by the criteria of Sanchez et al. ${ }^{13}$

These were: i) maximum (normal or nearnormal pulmonary X-ray); ii) medium (pleural effusion cleared in $50-80 \%$ ); iii) minimal (pleural effusion cleared in less than 50\%); iv)

In these cases, thoracic tube drainage was terminated when the daily amount of drainage decreased to less than $50 \mathrm{cc}$, pleural fluid culture became negative, and radiological healing and full expansion were detected.

All cases were assessed for a variety of parameters, such as the success of the two treatment modalities, duration of thoracic tube drainage, length of hospital stay (LHS), morbidity, mortality and cost. none (no changes). 


\section{Statistical analysis}

The descriptive statistics for the considered characteristics for the groups were expressed as median, mean, standard deviation, minimum and maximum values. The KruskalWallis test was used to compare for these characteristics. The $\mathrm{Z}$ test was used to compare rates. The statistical significance level of the calculations was accepted as 5\% and these calculations were performed using the SPSS (ver. 13) statistical pocket program.

\section{Results}

Twenty-two (40.74\%) of the cases were female and 32 (59.26\%) were male. Patients' characteristics at the time of diagnosis are presented in Table 1.

Pleural effusion was observed on the right in $31 \%$ of cases and on the left in $23 \%$ of cases. No bilateral effusion was observed. The most frequent symptoms were respiratory distress, cough, tachycardia and fever (Table 2).

Pleural infections were found to be consequent to primary empyema in $17 \%$ and to pneumonia in $37 \%$ of cases. Pathologies frequently accompanying thoracic empyema were additional pulmonary diseases, such as bronchiectasis, perforated hydatid cyst, and congenital pulmonary disease (20.37\%) (Table 2 ). The results of patients' blood, serum and pleural fluid samples, and microbiological analyses are presented in Table 3. Accordingly, bacterial growth in the blood culture was observed in 20 (37.03\%) cases, and in the pleural fluid culture in 38 (70.37\%) cases. The most frequently isolated (27.77\%) microorganism was the Streptococcus milleri group.

The postoperative results of the cases are shown in Table 4. Accordingly, with respect to the duration of symptoms following the operation, duration of thoracic tube drainage, and the length of stay in hospital, the VATS group demonstrated shorter times than the STK with a statistically significant difference between groups $(\mathrm{P}=0.0001)$.

The lungs were found to be fully expanded after the procedure in $19(70.37 \%)$ of the 27 cases receiving fibrinolytic treatment and in $21(77.77 \%)$ of the 27 cases undergoing the VATS procedure, and this was considered successful (Figure 1). The difference in success rates between the two groups was not significant $(\mathrm{P}=0.533)$. Following the fibrinolytic treatment, 8 (29.63\%) cases in whom the lungs had not fully expanded, underwent debridement by VATS. In one case, since lung expansion was not achieved, decortication was completed by thoracotomy. Six (22.23\%) cases who had undergone debridement by VATS were further converted to thoracotomy as full expansion was not achieved (Figure 1).

Table 1. Patients' characteristics at diagnosis.

\begin{tabular}{lccc} 
& STK $(\mathrm{n} .27)$ & VATIS $(\mathrm{n} .27)$ & $\mathrm{P}$ \\
Age (years) & $7.30 \pm 2.76$ & $8.74 \pm 2.60$ & 0.050 \\
Sex (M/F) & $17 / 10$ & $9 / 18$ & 0.023 \\
\hline Weight $(\mathrm{kg})$ & $25.30 \pm 6.31$ & $26.96 \pm 8.35$ & 0.412 \\
Height $(\mathrm{cm})$ & $121 \pm 16$ & $122 \pm 13$ & 0.445 \\
\hline Oxygen support (L/min) & $0.72 \pm 0.74$ & $0.69 \pm 0.56$ & 0.871 \\
Duration of symptoms in days & $8.0 \pm 1.7$ & $9.6 \pm 4.3$ & 0.413 \\
\hline Lateral effusion thickness (mm) & $73 \pm 39$ & $79 \pm 21$ & 0.844 \\
Area of shadowing (\%) & $51 \pm 21$ & $54 \pm 22$ & 0.816 \\
\hline
\end{tabular}

Complication rate was $12.96 \%$ of cases with no statistical difference between the two groups $(\mathrm{P}=0.589)$. In $4(12.81 \%)$ cases receiving fibrinolytic treatment, hypertension, hemorrhage, sudden chest pain and sudden aphonia developed. VATS was performed in 3 (11.11\%) cases; 2 cases had prolonged air leaks, and one had a wound infection. No mortality was observed.

The cases were followed-up monthly for the first three months and then on a yearly basis. There were no remission and all patients enjoy good health.

\section{Discussion}

Investigators who recommended VATS reported that fibrinolytic treatment is uncomfortable and that its resolution takes a long time. They also reported that it is not very successful in clearing out the loculation. ${ }^{14,15}$ Those who defended the fibrinolytic treatment emphasized that this method could be easily applied, decreases the rising cost of material use and preserves patients from the risk of morbidity posed by thoracic operations. ${ }^{16,17}$

Coote and Kayl18 in 2005 investigated the clinical results of operative and non-operative treatment in children and adults with empyema in the Cochrane Collaboration and reported that fibrinolytic treatment resulted in lower hospital costs in the early stages. In another study, it was reported that VATS required a shorter hospital stay and gave better results. ${ }^{19}$. However, these studies on only a few subjects showed that larger series are needed. While in their retrospective analysis Doski et al. ${ }^{9}$ showed that VATS led to a shorter hospital stay compared to fibrinolytics in children with empyema, Sonnappa et al.16 found a similar length of hospital stay (mean six days) and treatment success in their randomized prospective study comparing fibrinolytics and VATS decortications in children with empyema. In the present study, in 3 (13\%) of 30 cases for which VATS was applied the procedure was converted to mini thoracotomy, and in one case VATS had to be re-performed; an opera-
Table 2. Symptoms of the cases and accompanying diseases in the cases.

N. cases (\%)

$\begin{array}{lc}\text { Symptoms } & \\ \text { Fever }\left(>38^{\circ} \mathrm{C}\right) & 35(64.81) \\ \text { Cough } & 45(83.33) \\ \text { Respiratory distress } & 47(87.03) \\ \text { Pyrulent mucus } & 16(26.62) \\ \text { Cyanosis } & 5(9.25) \\ \text { Tachycardia } & 37(68.51) \\ \text { Pleuritic type chest pain } & 15(27.77) \\ \text { Abdominal pain } & 4(7.40) \\ \text { Severe anemia } & 9(16.66) \\ \text { Coexisting illness } & \\ \text { Cardiac disease } & 3(5.55) \\ \text { Additional respiratory disease } & 11(20.37) \\ \text { Diabetes mellitus } & 2(3.70) \\ \text { Joint disease } & 3(5.55) \\ \text { Gastro esophageal disease } & 6(11.11) \\ \text { Neurological disease } & 2(3.70) \\ \text { Kidney disease } & 2(3.70) \\ \text { Liver disease } & 2(3.70) \\ \text { Hematologic disease } & 1(1.85)\end{array}$

tion was necessary in 5 (18\%) of the 28 cases to which fibrinolytics were administered. Sonnappa et al.16 reported that fibrinolytic treatment should be the treatment of choice in consideration of cost.

In the 2008, American Pediatric Surgery Association Annual Meeting, St Peter et al. ${ }^{20}$ presented their prospective randomized studies in which they administered fibrinolytic agents through the thoracic tube and decortications through VATS. In this series, including 18 children in each group, the length of hospital stay was 6.89 days for VATS and 6.83 days for fibrinolytics. The cost of fibrinolytic treatment was lower than VATS ( $\$ 11,660$ vs $\$ 7575$, $\mathrm{P}<0.01)$. The failure of fibrinolytic treatment was $16.6 \%$.

In another study comparing these two treatment methods, there was no difference between the two groups with respect to the length of hospital stay, although VATS treatment was expected to be shorter.14 Except for cost, there were no significant differences in any secondary result parameters between groups. In this study, failure rates were similar 
between the two groups.

In the present study, VATS had advantages with respect to the duration of thoracic tube drainage, duration of symptoms after the procedure, and the length of hospital stay $(\mathrm{P}=0.0001)$. Fibrinolytic treatment had cost advantages $(\mathrm{P}=0.0001)$ (Table 4$)$. The success rate in those undergoing fibrinolytic treatment was $70.37 \%$ and the failure rate was $29.62 \%$; these were $77.77 \%$ and $22.22 \%$ for VATS, respectively. There was no significant difference between the two groups in success and failure rates $(\mathrm{P}=0.533)$.

The failure rates for both groups in this study were higher than that of other series (fibrinolytics 5 -16\%, VATS $0-20 \%$ ). $9,19,20$ This result may be due to the fact that $76.3 \%$ of patients did not receive any treatment, and in contrast to other studies $9,15,19,20$ most of the cases (57.4\%) were in stage III.

Table 3. Patients' blood or serum, pleural fluid, and microbiological characteristics.

\begin{tabular}{|c|c|c|c|}
\hline Analyzed material/ parameters & STK (n. 27) & VATS (n. 27) & $\mathbf{P}$ \\
\hline \multicolumn{4}{|l|}{ Blood or serum } \\
\hline White blood cell $(/ \mu \mathrm{L})$ & $15,516 \pm 6,018$ & $18,665 \pm 6,551$ & 0.586 \\
\hline $\mathrm{Hb}(\mathrm{g} / \mathrm{L})$ & $10.0 \pm 2.3$ & $9.6 \pm 1.3$ & 0.484 \\
\hline PLT $\left(/ \mathrm{mm}^{3}\right)$ & $395,368 \pm 236,914$ & $454,134 \pm 236,566$ & 0.390 \\
\hline $\operatorname{ESR}(\mathrm{mm} / \mathrm{h})$ & $71.9 \pm 31.3$ & $94.8 \pm 36.6$ & 0.038 \\
\hline C-reactive protein > $100 \mathrm{mg} / \mathrm{L}, \mathrm{n}(\%)$ & $11(40.74)$ & $15(55.55)$ & 0.062 \\
\hline \multicolumn{4}{|l|}{ Pleural fluid } \\
\hline Turbid or purulent, n (\%) & $18(66.66)$ & $14(51.85)$ & 0.262 \\
\hline $\mathrm{pH}$, mean $\pm \mathrm{SD}$ & $7.25 \pm 0.49$ & $7.08 \pm 0.42$ & 0.451 \\
\hline Glucose, mg/dL & $30(0-241)$ & $5(1-111)$ & 0.173 \\
\hline Lactate dehydrogenase,IU/L & $2.559(309-40.990)$ & $1.340(679-23.600)$ & 0.361 \\
\hline \multicolumn{4}{|l|}{ Microbiological characteristics } \\
\hline Positive blood culture n. (\%) & $11(40.74)$ & $9(33.33)$ & 0.572 \\
\hline Positive pleural-fluid culture n. (\%) & $21(77.77)$ & $17(62.96)$ & 0.227 \\
\hline \multicolumn{4}{|l|}{ Streptococcus milleri group } \\
\hline (S. intermedius, S. constellatus, S. mitis) & $10(37.03)$ & $5(18.5)$ & 0.121 \\
\hline S. pneumoniae & $5(18.5)$ & $7(25.92)$ & 0.511 \\
\hline Other streptococci & $2(7.40)$ & $3(11.11)$ & 0.638 \\
\hline Enterobacteriaceae & $3(11.11)$ & $4(14.81)$ & 0.685 \\
\hline Anerobic bacteria & $4(14.81)$ & $3(11.11)$ & 0.685 \\
\hline \multicolumn{4}{|l|}{ Staphylococcus aureus } \\
\hline Antibiotic-sensitive & $2(7.40)$ & $3(11.11)$ & 0.638 \\
\hline Methicillin-resistant & $3(11.11)$ & $2(7.40)$ & 0.999 \\
\hline Enterococci & $2(7.40)$ & $2(7.40)$ & 0.999 \\
\hline Other & $2(7.40)$ & $1(3.70)$ & 0.551 \\
\hline
\end{tabular}

Table 4. Postoperative results of the cases.

\begin{tabular}{|c|c|c|c|}
\hline & STK & VATS & $\mathbf{P}$ \\
\hline Post-therapy days of $\mathrm{O}^{2}$ support & $2.3 \pm 1.4$ & $2.1 \pm 2.0$ & 0.911 \\
\hline Afebrile days after intervention & $3.9 \pm 2.1$ & $3.4 \pm 2.4$ & 0.782 \\
\hline Analgesia doses & $22.1 \pm 18.9$ & $25.4 \pm 13.1$ & 0.561 \\
\hline Chest tube removal time & $9.48 \pm 2.50$ & $6.56 \pm 1.55$ & 0.0001 \\
\hline Duration of hospital stay & $10.37 \pm 2.29$ & $7.41 \pm 1.45$ & 0.0001 \\
\hline Duration of symptoms after intervention & $6.78 \pm 1.69$ & $3.78 \pm 1.25$ & 0.0001 \\
\hline \multicolumn{4}{|l|}{ Fluid drainage } \\
\hline Initial drainage amount & $394.93 \pm 220.65$ & $379.19 \pm 230.14$ & 0.786 \\
\hline Postoperative drainage amount & $850.59 \pm 301.91$ & $865.78 \pm 444.41$ & 0.884 \\
\hline Total drainage amount & $1245.52 \pm 361.43$ & $1243.96 \pm 552.81$ & 0.990 \\
\hline \multicolumn{4}{|l|}{ Postoperative respiratory function test } \\
\hline FVC (\%) & $62 \pm 7.021$ & $55 \pm 10.13$ & 0.467 \\
\hline FEV1 (\%) & $72 \pm 8.141$ & $77 \pm 6.231$ & 0.618 \\
\hline FEV1/FVC (\%) & $112 \pm 4.268$ & $119 \pm 3.233$ & 0.578 \\
\hline PEF (\%) & $64 \pm 5.012$ & $50 \pm 8.141$ & 0.312 \\
\hline MEF 25-75 (\%) & $84 \pm 3.782$ & $72 \pm 5.897$ & 0.297 \\
\hline N. cases with successful intervention & $19(70.37)$ & 21 (77.77) & 0.533 \\
\hline Total cost & $\begin{array}{c}612.00 \pm 114.06 \mathrm{TRY}^{*} \\
\left(386.672 \pm 72.06 \mathrm{USD}^{* *}\right)\end{array}$ & $\begin{array}{c}1.515 .00 \pm 217.14 \mathrm{TRY}^{*} \\
\left(957.487 \pm 137.238 \mathrm{USD}^{* *}\right)\end{array}$ & 0.0001 \\
\hline
\end{tabular}

\section{References}

1. Sahn SA. Use of fibrinolytic agents in the management of complicated parapneumonic effusions and empyemas. Thorax 1998;53:65-72.

2. Cohen G, Hjortdal V, Ricci M, et al. Primary thoracoscopic treatment of empyema in children. J Thorac Cardiovasc Surg 2003; 125:79-84.

3. Chonmaitree T, Powell KR. Parapneumonic pleural effusion and empyema in children: review of a 19 year experience, 1962-1980. Clin Pediatr 1983; 22:414-9.

4. Andrews NC, Parker EF, Shaw RR, et al. American Thoracic Society: Management of nontuberculous empyema. Am Rev Respir Dis 1962;85:935-6.

5. Light RW. Parapneumonic effusions and empyema. Proc Am Thorac Soc 2006;3:7580.

6. Özçelik C, Ulku R, Onat S, et al. Management of postpneumonic empyemas in children. Eur J Cardiothorac Surg 2004;25:1072-8.

7. Krishnan S, Amin N, Dozor AJ, Gustavo S. Urokinase in the management of complicated parapneumonic effusions in children. Chest 1997;112:1579-83.

8. Pollak JS, Passik CS. Intrapleural urokinase in the treatment of loculated pleural effusions. Chest 1994;105:868-73.

9. Doski JJ, Lou D, Hicks BA, et al. Management of parapneumonic collections in infants and children. $\mathrm{J}$ Pediatr Surg 2000;35:265-70.

10. Patton RM, Abrams RS, Gauderer MWL. Is thoracoscopically aided pleural debridement advantageous in children? Am Surg 1999;65:69-72.

11. Talib SH, Verma GR, Arshad M, et al. Utility of intrapleural streptokinase in management of chronic empyemas. J Assoc Physicians India 2003;51:464-8.

12. Miller MA, Ben-Ami T, Daum RS. Bacterial pneumonia in neonates and older children. In: Taussig LM, Landau LI, Le Souef PN, Morgan WJ, Martinez FD, Sly PD (eds) 
Pediatric respiratory medicine. Mosby, St. Louis, MO, USA, 1999, pp 595-664.

13. Jerjes-Sanchez C, Ramirez-Rivera A, Elizalde JJ, et al. Intrapleural fibrinolysis with streptokinase as an adjunctive treatment in hemothorax and empyema. Chest 1996;109:1514-9.

14. Bouros D, Antoniou KM, Chalkiadakis G, et al. The role of videoassisted thoracoscopic surgery in the treatment of parapneumonic empyema after the failure of fibrinolytics. Surg Endosc 2002;16:151-4.

15. Sonnappa S, Cohen G, Owens CM, et al.
Comparison of Urokinase and Videoassisted Thoracoscopic Surgery for Treatment of Childhood Empyema. Am J Respir Crit Care Med 2006;174:221-7.

16. Misthos P, Sepsas E, Konstantinou M, et al. Early use of intrapleural fibrinolytics in the management of postpneumonic empyema. A prospective study. Eur J Cardiothorac Surg 2005;28:599-603.

17. Ulku R, Onat S, Kiliç N. Intrapleural fibrinolytic treatment of multiloculated pediatric empyemas. Minerva Pediatr 2004;56:419-23.
18. Coote N, Kay E. Surgical versus non-surgical management of pleural empyema. Cochrane Database Syst Rev 2005;19: CD001956.

19. Wait MA, Sharma S, Hohn J, Dal Nogare A. A randomized trial of empyema therapy. Chest 1997;111:1548-51.

20. St. Peter SD, Tsao K, Spilde TL, et al. Thoracoscopic decortication versus tube thoracostomy with fibrinolysis for empyema in children: a prospective, randomized trial. Journal of Pediatric Surgery 2009;44: 106-11. 